\title{
The Adolescent Girls Empowerment Program: Lessons learned from the pilot test program
}

\author{
Karen Austrian \\ Population Council \\ Natalie Jackson Hachonda \\ Population Council \\ Paul C. Hewett \\ Population Council
}

Follow this and additional works at: https://knowledgecommons.popcouncil.org/departments_sbsr-pgy

Part of the Demography, Population, and Ecology Commons, Family, Life Course, and Society

Commons, Gender and Sexuality Commons, International Public Health Commons, and the Medicine and

Health Commons

How does access to this work benefit you? Let us know!

\section{Recommended Citation}

Austrian, Karen, Natalie Jackson Hachonda, and Paul C. Hewett. 2013. "The Adolescent Girls

Empowerment Program: Lessons learned from the pilot test program." Lusaka: Population Council. 


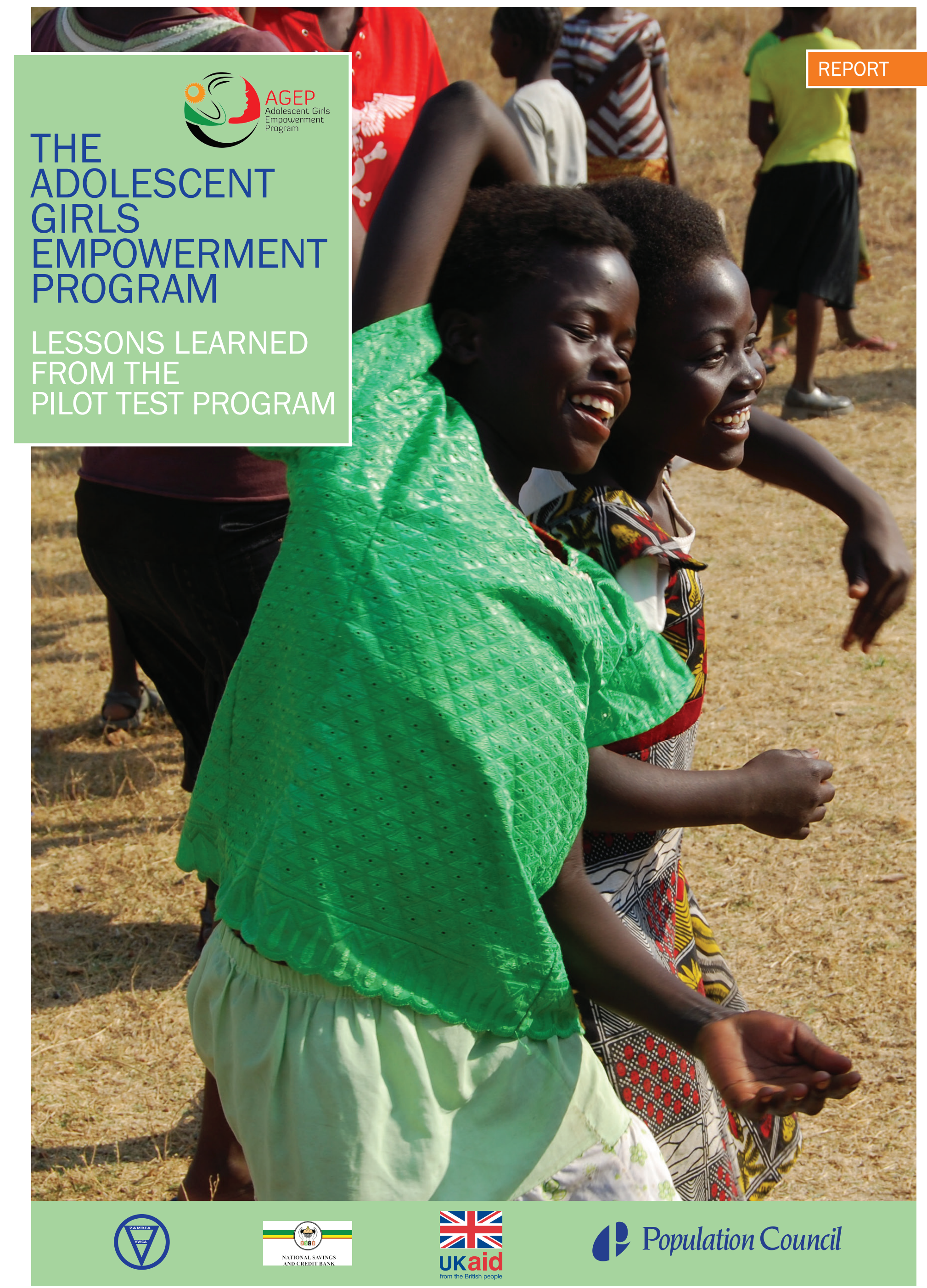




\section{Population Council}

The Population Council confronts critical health and development issues-from stopping the spread of HIV to improving reproductive health and ensuring that young people lead full and productive lives. Through biomedical, social science, and public health research in 50 countries, we work with our partners to deliver solutions that lead to more effective policies, programs, and technologies that improve lives around the world. Established in 1952 and headquartered in New York, the Council is a nongovernmental, nonprofit organization governed by an international board of trustees.

(C) 2013 The Population Council, Inc.

Population Council

One Dag Hammarskjold Plaza

New York, NY 10017 USA

Tel: 212-339-0500

Fax: 212-755-6052

Population Council

Plot \#3670 No. 4 Mwaleshi Road

Olympia Park

Lusaka

Zambia

10101

Tel: +260 211295925

Fax: +260 211295925

agep@popcouncil.org

www.popcouncil.org

Suggested citation: Austrian, K., Jackson Hachonda, N., and Hewett, P. 2013. “The Adolescent Girls Empowerment Program: Lessons learned from the pilot test program." Lusaka: Population Council.

\section{AUTHORS}

KAREN AUSTRIAN, Associate, is based in the Population Council's Nairobi, Kenya office and is the AGEP Principal Investigator/Project Director.

NATALIE JACKSON HACHONDA, Senior Program Officer, is based in the Population Council's Lusaka, Zambia office and manages the day-to-day operations of the AGEP program.

PAUL C. HEWETT, Ph.D., Senior Associate, is based in the Population Council's Lusaka, Zambia office and is the AGEP Lead Investigator.

Photographer: Natalie Jackson Hachonda 


\section{INTRODUCTION}

Adolescent girls ${ }^{1}$ in Zambia face a range of risks and vulnerabilities that compromise their healthy development from girls into young women. And at the same time, girls in Zambia lack the social, health and economic assets to mitigate these risks. The issues that girls are confronted with-high rates of gender-based violence, unsafe sex that puts girls at risk for unwanted pregnancy and HIV infection, school dropout, lack of economic resources and income-generating options, lack of agency and participation-are linked together through their root causes.

\section{SOCIAL ISOLATION}

Lack of social protection and social isolation are risks for adolescent girls in Zambia, limiting their agency and voice, and making it difficult to access societies' institutions-e.g., health facilities. Adolescents living apart from one or both parents may be socially isolated, may lack the economic resources needed to go to school, and may have to carry some incomegenerating burden both for themselves and for family members. In Zambia, a third of girls do not live with either parent; the situation in Lusaka is the most bleak, with 36 percent of girls living apart from both parents (as compared to 28 percent of boys).

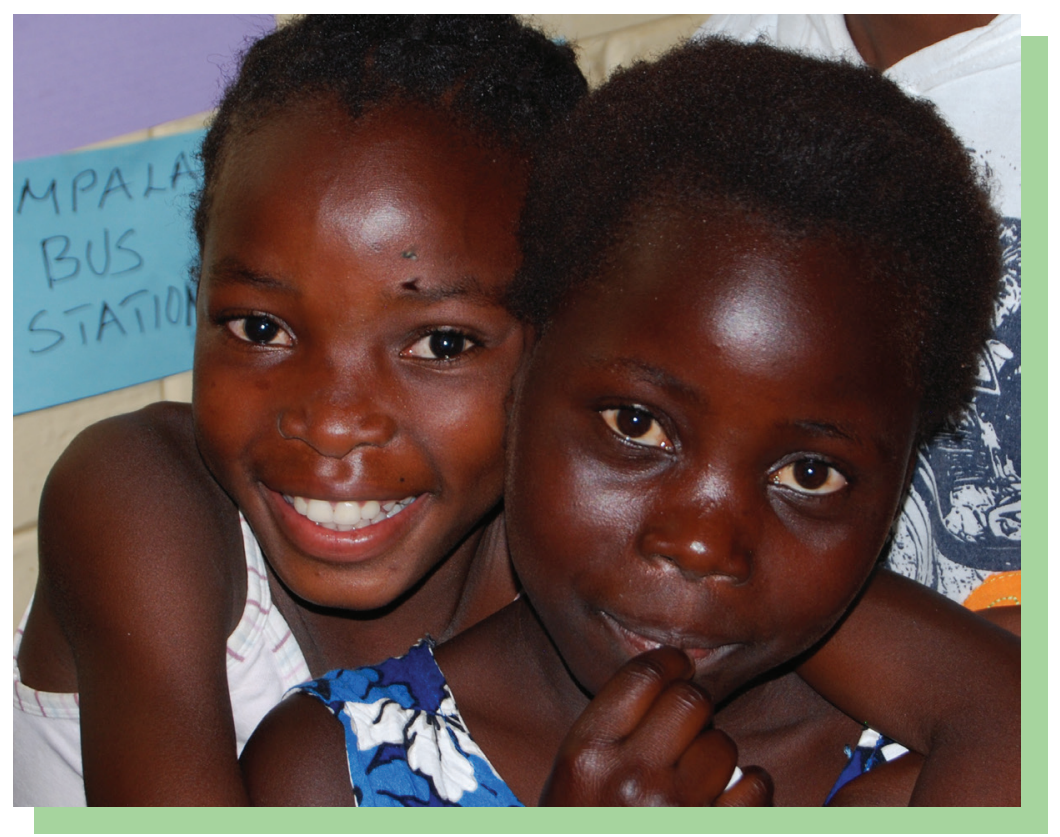

\section{EARLY MARRIAGE}

Married girls also have limited social, health, and economic assets. Child brides often experience a sudden shrinking of their social networks as they move to their husbands' residence, leaving them with few, if any, friends and peers. While parents may attempt to marry their daughters at an early age for apparent economic stability, in reality early marriage leaves girls with limited control over resources, highly restricted mobility and little or no power in their new households. Thus married girls may face significant challenges in negotiating safe sexual relations. In Zambia, according to the 2007 DHS, 8.5 percent of girls ages 20-24 were married by age 15 . This percentage is higher in several provinces, with a high of 19 percent in Northern Province. ${ }^{2}$ Nationally, 53 percent of rural and 26 percent of urban girls are married by 18; currently, 17.8 percent of 15-19-year-old girls are married or in a union. These girls are extremely vulnerable, are sexually active, have a unique set of needs, and are missed by both general youth programs and by general sexual and reproductive health programs for women.

1 For this document, adolescent girls are defined as girls ages 10-19.

2 Unless otherwise noted, data in this section come from "The Adolescent Experience In-Depth: Using Data to Identify and Reach the Most Vulnerable Young People: Zambia 2007.” New York: Population Council, 2009. 


\section{EDUCATION}

Education is a critical component of a healthy transition to adulthood. For example, being in school has been associated with delays in the age at first sex, marriage, and childbearing. However, in both rural and urban Zambia, disaggregated data from the 2007 DHS show that girls have lower levels of school enrollment than boys. Furthermore, school enrollment levels for girls in urban areas are lower than levels for boys in rural areas. For both urban and rural girls, school dropout begins at age 13. One-third of girls ages 10-14 in Zambia are already off course with their schooling-meaning that they have either never been in school, are not currently in school, or are in school but more than two years behind grade-for-age. When comparing girls' non-enrollment to boys', levels are similar for the 1014 year old group (10 percent), but the gender disparity is clear among older adolescents with 44.3 percent of girls ages 15-19 not in school as compared to 22.2 percent of boys. In other words, boys show much less decline in enrollment rates between younger and older adolescents, but for girls the decline is substantial. Therefore, interventions that are school-based miss large segments of the adolescent girl population-and often those who are most vulnerable.

\section{GENDER-BASED VIOLENCE (GBV)}

Lack of social protection and voice leaves girls exposed to violence, both physical and sexual. More than 28 percent of 15-24-year-old females have experienced physical violence, and in many regions it is higher, with the highest at $60 \%$ in Copperbelt Province. A study by the Population Council with girls ages 15-24 in urban slums in Lusaka confirms pervasive levels of violence among adolescent girls at home and in the community (Brady et al. 2009). School, a place that is supposed to be protective, is also not safe for girls.

Seventy percent of girls in that study reported having been teased or sexually harassed in school and 53 percent reported that girls in their school are molested. Eighty-six percent reported that girls their age are pressured to do things they don't want to in exchange for money. The issues also go beyond experience of violence, but also acceptance of it. Data from the 2007 DHS confirms that in Zambia harmful gender norms are formed by an early age. Among 15-24 year old females, 16.2 percent of think that wife beating is completely justified and 63.1 percent believe that it is justified in certain circumstances. Therefore, it is critical to reach girls early, addressing gender norms and rights, in an effort to reduce violence against girls.

\section{HIV AND OTHER HEALTH RISKS}

A significant health risk to girls in Zambia is HIV. The threat is particularly acute among young women and girls with limited social and economic assets who are unable to avoid, manage, or leave unsafe sexual relationships, whether inside or outside of marriage (Bruce 2007). In Zambia, HIV prevalence is more than 2:1 female to male, meaning that girls are the ones most at risk in that age group. Among 15-19-year-olds, 5.7 percent of females are infected as compared to 3.6 percent of males. The gender disparity increases in the 20-24-year-old group with 11.8 percent of females being infected as compared to 5 percent of males. Due to the gender-based and economic inequalities present in many marriages and sexual relationships, women, especially girls, may find it difficult to communicate about HIV and negotiate condom use with their partners. Therefore, while knowledge of and access to HIV testing and other services are important, they are not sufficient to ensure HIV prevention. Girls must have strong social, health and economic assets in order to gain more control within their sexual relationships. 
Additional health risks-especially early pregnancy, unsafe abortion, and STIs-result from high levels of unprotected sex. In Zambia, only 26 percent of first sexual experiences are within marriage, and among 15-19-year-old never-married girls, a third in urban settings and $40 \%$ in rural settings had had sex. Overall, 14.3 percent of 20-24-year-old women reported first sex before age 15 and 61 percent before age 18. Married and unmarried sexually active adolescents need information, social support for informed decision making, and access to services and technologies to effectively maintain their sexual and reproductive health. The large age gap between girls and their partners, which can result from financial dependency, often puts girls at a social and economic disadvantage, which compromises their ability to avoid violence and negotiate healthy sexual behavior. In Zambia there is a large unmet need for contraception among adolescents and young women, with only 46 percent of never-married sexually active girls ages 15-24 having ever used contraception.

Assets that prevent pregnancy among girls are critical because early motherhood is linked to school dropout, social isolation, and early marriage. Accord-

Assets that prevent pregnancy among girls are critical because early motherhood is linked to school dropout, social isolation, and early marriage. ing to the 2007 Zambia DHS, 28.5 percent of all 15-19-year-olds have been pregnant or had a child (14.5 percent among those who have never been married). However, despite the high levels of risk for HIV and unwanted pregnancy, less than 15 percent of girls 15-19 have had an HIV test in the past 12 months, and only 39 percent of sexually active unmarried 15-24-year-olds used a condom at last sex.

The situation described above is a challenging one for adolescent girls in Zambia. Across a range of issues-education, social support, safety, and sexual and reproductive healththey are at a disadvantage compared to their male peers. This added vulnerability for adolescent girls in Zambia is the basis for designing an intervention that a) focuses on adolescent girls ages $10-19$ and b) selects girls for the program with the intention of including those with the most vulnerabilities.

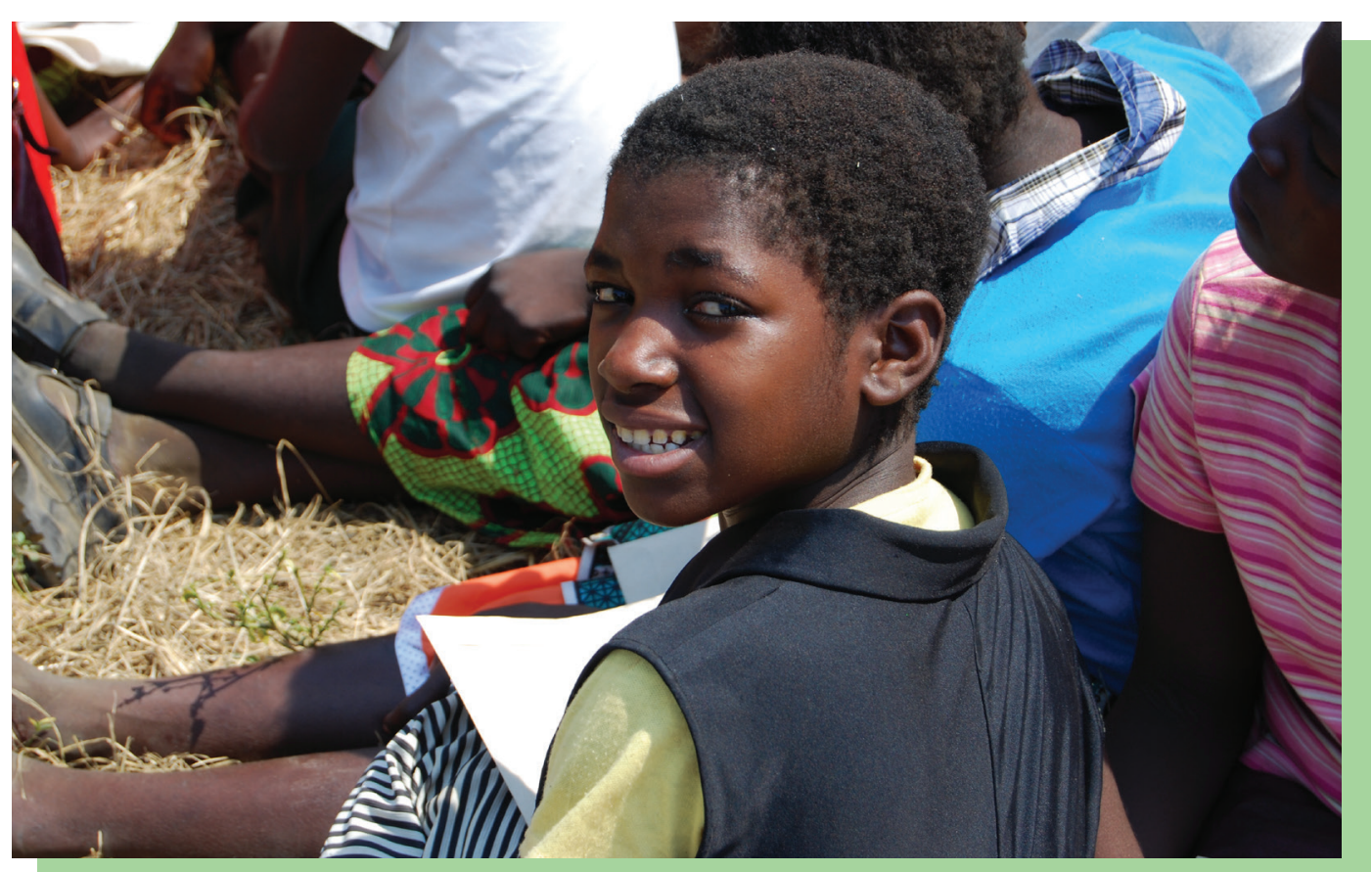




\section{PROGRAM DESCRIPTION}

The Adolescent Girls Empowerment Program (AGEP) is comprised of three major components: 1) safe spaces groups in which girls meet once a week over the course of two years for training on sexual and reproductive health, life skills and financial education. Groups are facilitated by a mentor, a young female from the same community as the girls; 2) a health voucher that girls can use at contracted private and public facilities for general wellness and sexual and reproductive health services; and 3) a saving account that has been designed to be girl-friendly.

\section{SAFE SPACES}

The core of AGEP is a safe spaces component. Implemented in partnership with YWCA Zambia, safe spaces are weekly girls' group meetings in which 20 to 30 girls get together with a mentor-a young woman from their community-for short training sessions on a variety of topics as well as a chance to discuss their experiences of the past week. These regular group sessions serve two critical functions: 1) they build a platform in which girls can be reached with interventions and educational topics, and 2) they build social assets, including friendships, trusting relationships, and self-esteem, which have a positive influence on their livelihood and health. The group meetings become an integral part of what girls expect in their lives in these communities and can be sustained in the long term via cultural change.

During the introductory meeting, girls are assigned to one of three types of groups: 10-14-year-olds, 15-19-year-olds, or married girls/mothers. Each group is assigned a mentor, and a regular meeting day, time and location is chosen. Most of the groups meet in places that are free of charge, although a few have to rent the space. If a girl misses more than two or three consecutive meetings, the mentor conducts a home visit to identify the reason for the girl's absence. In addition to the weekly group meetings, parents/guardians/husbands meetings are held two to three times per year.

Mentors-Each master site has 24 mentors. During the community sensitization process, a job posting is circulated in the community for the mentor post. Mentors must be between the ages of 20 and 40, female, able to speak English and the local language, and have completed secondary school. Applicants are interviewed and 30 mentors per site were selected for training. At each site, an initial training of trainers (TOT) is held and the 24

Safe Spaces are weekly girls' group meetings in which 20 to 30 girls get together with a mentor for short training sessions on a variety of topics as well as a chance to discuss their experiences of the past week. final mentors are selected. An additional six mentors are selected as alternates in case of mentor dropout. After two to three months of group meetings, a refresher training was held. A second refresher training will be held in the second year of the program. In addition, mentors meet once a month with the site coordinator. At these meetings mentors submit their attendance data, discuss successes and challenges, and receive short training sessions. Mentors get paid a monthly stipend and receive rain coats and gum boots for the rainy season. In addition, mentors in the rural sites receive a bicycle. 


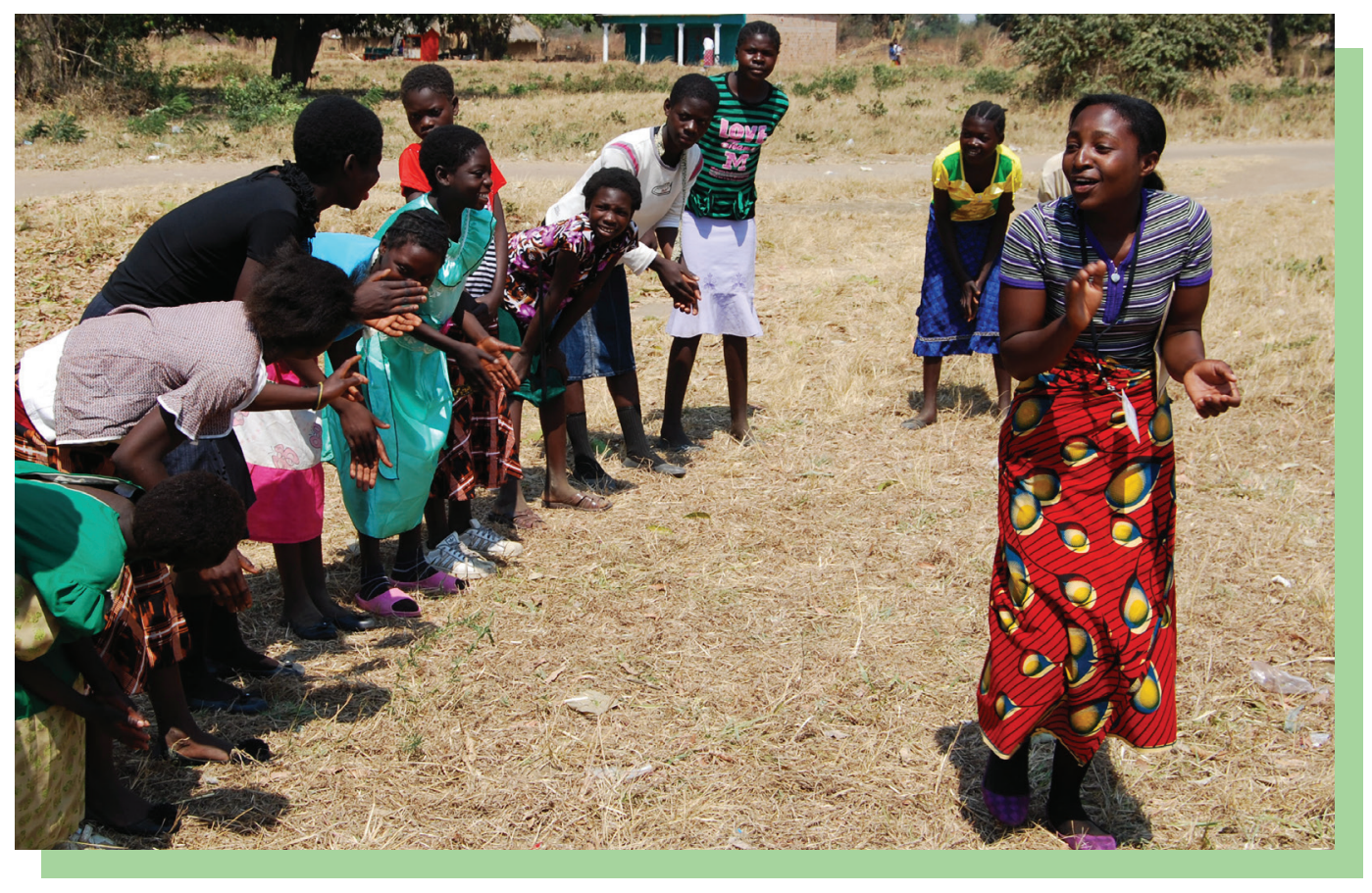

Curriculum-AGEP has developed two curricula: 1) a health and life skills (HLS) curriculum and 2) a financial education curriculum. The HLS curriculum includes sessions on reproductive health, HIV, life skills, gender and gender-based violence, leadership and human rights. The financial education curriculum includes sessions on saving, budgeting, financial negotiation, and earning money. In addition, girls in the savings "arm" of the program have a session on the Girls Dream account (see below). All mentors use the same curriculum and are given the order in which the sessions should be delivered to ensure standardization across all groups. During the pilot test, the two curricula described above were also tested. Each went through a review process involving feedback from girls, mentors, government and NGO stakeholders. The final curricula were laid out to be more user-friendly and were printed for rollout.

\section{HEALTH VOUCHER}
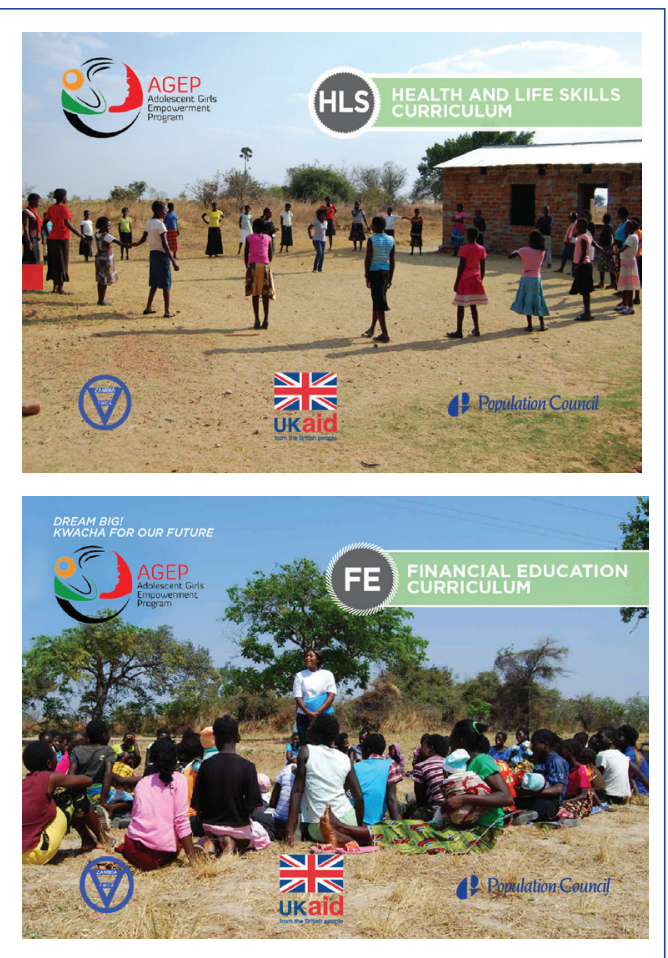

In partnership with the Ministry of Health $(\mathrm{MoH})$ and Ministry of Community Development Mother and Child Health (MCDMCH), the Council has developed a health voucher for AGEP participants that will be redeemable for health services at partner public and private health providers. To date, participating health providers include the $\mathrm{MoH}$, MCDMCH, Planned Parenthood Association of Zambia (PPAZ), and the Coptic Clinic in New Kanyama. The Council has a contract with each provider that outlines the terms of the voucher, service provision, quality assurance, and payment. The services covered include basic wellness exams and age-appropriate sexual and reproductive health services. While services at public facilities are currently free in Zambia, the voucher provides an incentive to the health providers to improve the supply of adolescent-friendly health services, while giving vouchers to girls increases demand. 


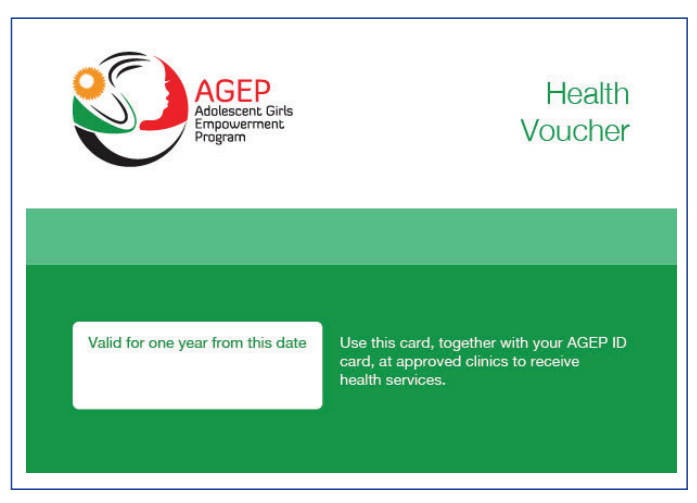

Two-thirds of girls in AGEP will receive the voucher (see page 7 for research design). The voucher will be valid for one year. If a girl drops out of the safe space program, she can continue to use the voucher until its expiration date. The Council will distribute a second voucher at the start of the second year through the safe space mentors. To prevent people outside of the group from using the voucher, each girl will receive a program photo ID card with a serial number to be used during the authentication process when accessing a service.

The voucher will consist of a simple scratch card with two series of scratch panels: 1) The first series will have six scratch panels for primary consultations with the following restrictions:

- The girls may access a consultation six times at the same provider or she may access a consultation six times at a different provider each time; and

- The six primary consultations can be used multiple times for the same issue (for example six consultations for a wellness check or for FP), or they can be used for a different issue each time (for example, the first time for a wellness check, second time for a pregnancy test, third time for STI treatment, fourth time for a change of FP method, fifth time for a pregnancy test, and sixth time for a first antenatal visit). After six primary consultations the girl can no longer use the voucher to pay for primary consultations.

The second series will have seven scratch panels to be used for follow-up consultations for simple procedures such as follow-up FP injections or a RPR test. The same restrictions for the primary consultations stated above apply to the follow-up consultations.

\section{SAVINGS ACCOUNT}

The Population Council has worked in partnership with the National Savings and Credit Bank (NatSave) and Making Cents International to develop the "Girls Dream" Savings Account for AGEP girls. The NatSave account has a low minimum balance of KR 2.5 (\$0.50) to open, and any amount can be deposited or withdrawn with no fee. While girls are able to make deposits on their own, in order to conform to the Zambian legal minimum age of 18 for opening accounts, girls will select a co-signatory-a woman aged 18 or older-to assist with account opening and withdrawals.

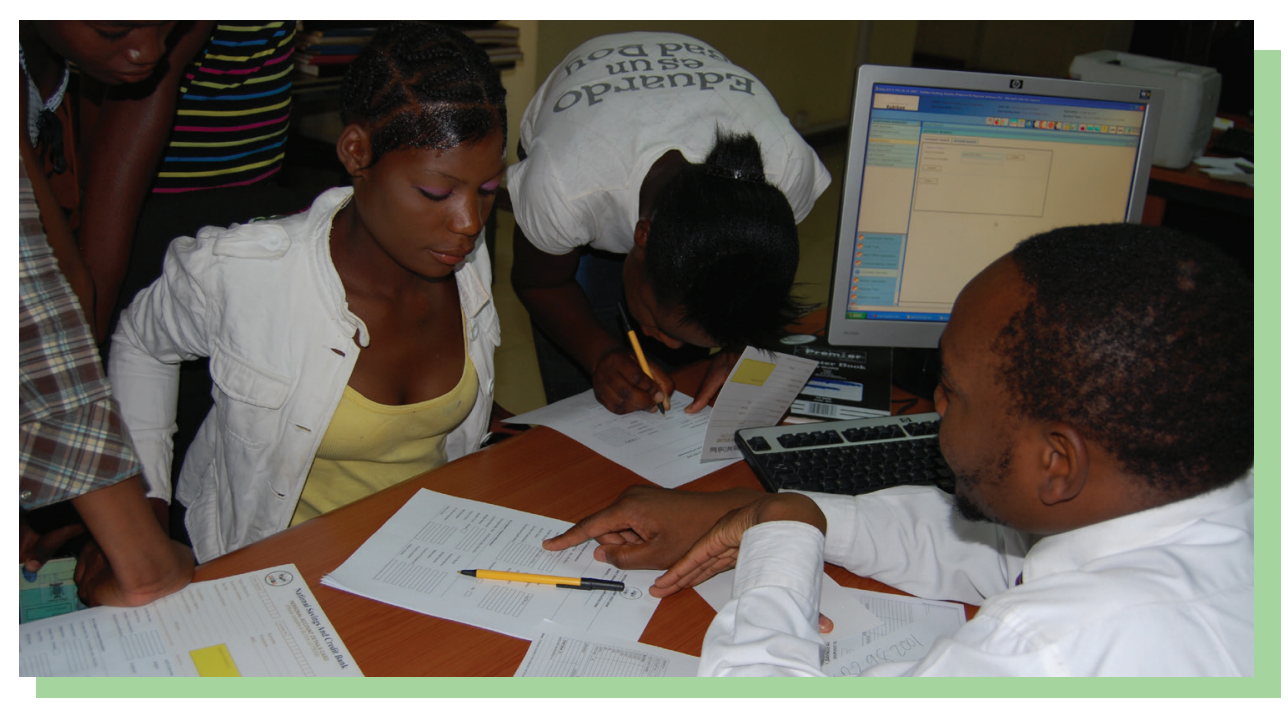


Prior to account opening, mentors in the savings arm are trained by AGEP staff on the savings account, and an orientation session is held with the girls and their co-signatory to inform them of the account and begin the account opening process. Finally, a field trip to the branch is organized for girls and their co-signatory to complete the account opening process. This three-step process is uniform across all ten sites to ensure standardization.

\section{RESEARCH DESIGN}

A randomized control trial (RCT) using a cluster design is being used to evaluate the impact of AGEP. The research aims to identify the impact of the intervention on the following key indicators: HIV prevalence, HSV-2 prevalence, age at first sex, age at first birth, contraceptive use, experience of gender-based violence, and educational attainment. The program is being implemented in three versions to assess the added effect of each program component:

1) Safe spaces only

2) Safe spaces + health voucher

3) Safe spaces + health voucher + savings account

Each AGEP site is made up of between 20 and 45 Census Supervisory Areas (CSAs), out of which 16 have been randomly selected (four per program curriculum and four as a control).

Before the program started a household listing was conducted in each of the CSAs, generating a list of households with adolescent girls ages 10-19 in each CSA. Based on information collected during the household listing, the most vulnerable 1,200 girls in each site were invited to the program. Invitations were hand-delivered to the household and girls and their guardian were invited to attend an introductory meeting. During the pilot test, a second introductory meeting was held in which girls were assigned to their group; thereafter, each group began to meet weekly progressing through the AGEP curricula.

The research design was tested during the pilot phase-specifically the process of the household listing, vulnerability selection, invitation process, and introductory meetings. The full study began during the program rollout. This process started with the same household listing described above conducted in 16 CSAs in each of the ten sites, for a total of 160 CSAs and approximately 85,000 households. The baseline survey will be conducted with approximately 4,900 unmarried girls ages $10-19$ being interviewed. All girls in the study will

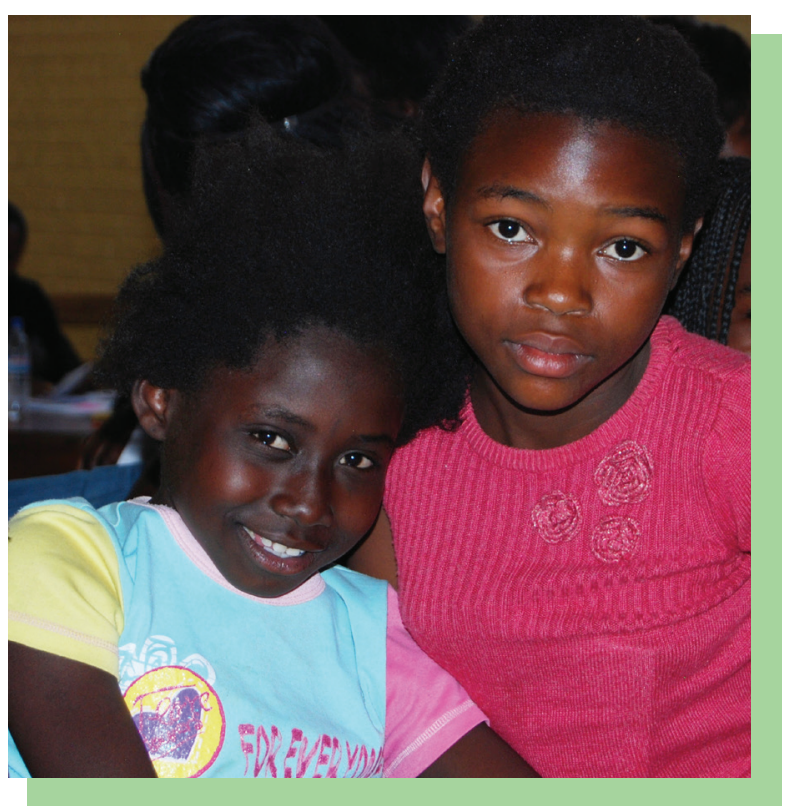
be interviewed about their schooling history, savings activity, livelihoods, social assets, gender norms, nutrition, literacy, numeracy and cognitive skills. In addition, 15-19-yearolds (approximately 2,350) will be tested for HIV and HSV-2, and asked questions about their sexual behavior and experience of sexual violence. The survey will be repeated on an annual basis for four additional years, with the inclusion of the HIV and HSV-2 testing after two years (at the end of the intervention) and after four years (the final round of data collection). 


\section{IMPLEMENTING THE PILOT PROGRAM}

AGEP began with a pilot test of all three program components, and the research pieces described above, in mid-2012. One urban site, the Matero compound in Lusaka District, and one rural site, Chibombo District in Central Province, were selected as the pilot test sites. The two sites were representative of urban and rural locations, near a NatSave branch (Chibombo girls used the branch in Kabwe town, about 55 kilometers away) and close enough to Lusaka so that they could be closely monitored by program staff.

The pilot test aimed not only to benefit a select number of girls, but also to serve as a critical time in which to identify the strengths and weaknesses of the intervention and make the necessary changes prior to the rollout. In the pilot period, out of 1,200 invited girls for each site, 762 girls were enrolled in Matero and 829 in Chibombo, for a total of 1,591. Of that, 40 percent and 43 percent, respectively, attend on a weekly basis.

\section{KEY LESSONS}

The following section describes the key lessons learned for each component of the AGEP intervention and the changes for the rollout period that resulted from those lessons.

\section{SAFE SPACES}

\section{Mentor Recruitment and Monitoring}

One challenge in the pilot was that some mentors, especially in the rural areas, lived quite far from their CSAs, which resulted from an uneven distribution of participants and mentors among the CSAs. Therefore, it took the mentors longer to get to the meetings, and they were less accessible to the girls outside of the meeting times. Another challenge was that some mentors dropped out, and others were asked to leave due to poor performance. The AGEP program team assessed these issues and proposed the following changes for the rollout of the main program.

\section{RECOMMENDATIONS/CHANGES FOR ROLLOUT:}

- Select mentors after CSAs have been selected so that the right number of mentors come from each CSA in which the program is being implemented

- Include 35 mentors in each training to provide a larger pool of mentors to choose from

- Select 4-6 alternate mentors per site and continue to include these mentors in trainings so that if they need to be brought in they are up to date on necessary trainings.

\section{Mentor Performance}

One problem with mentor performance during the pilot was that unacceptably high numbers of mentors either a) came late to their group meetings, b) did not attend their group meetings and asked someone to substitute for them, and/or c) did not attend group meetings and did not arrange for an alternate mentor. Poor/inconsistent attendance of mentors affected girls' attendance as they were no longer confident that the group meeting would always take place as scheduled.

\section{RECOMMENDATIONS/CHANGES FOR ROLLOUT:}

- Outline strict attendance requirements for mentors in their contracts, with penalties for violation including deductions from their monthly stipend. 


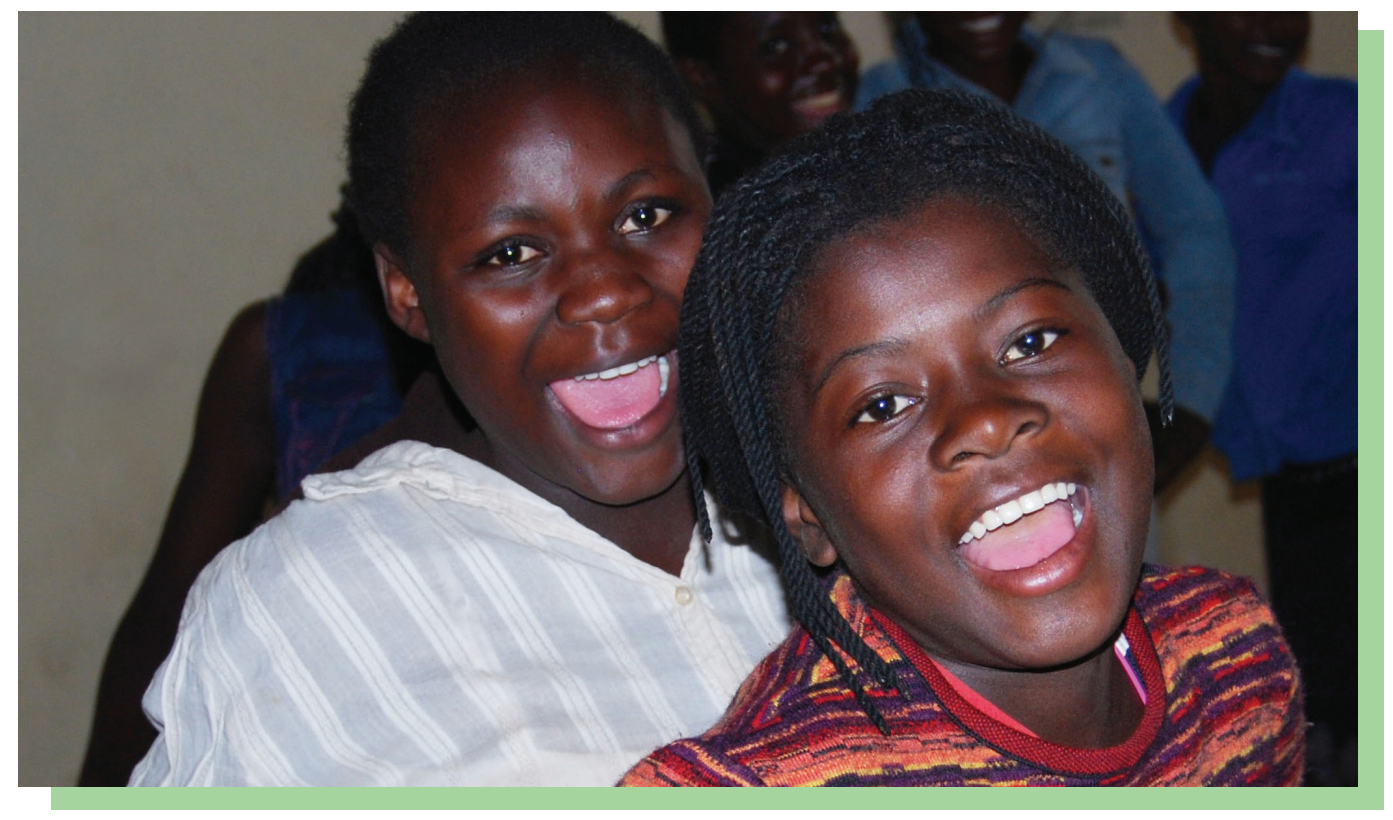

eRegistration and Attendance System

It is critical for a program of this size to monitor attendance at group meetings in as close to real-time as possible. With an anticipated $35,000+$ meetings to be held over the rollout period, it was clear that the paper register system for attendance used during the pilot would not be sufficient. Staff in the field need to know immediately whether or not meetings were held, how many girls attended, what sessions were covered, etc. to ensure high program quality. The only way to do this in the future is electronically. For the rollout, mentors will be given mobile phones with an app that will allow them to enter their weekly attendance data from the field. The data will be linked to a web system that tracks each girl and her participation. The data will be critical for monitoring program quality and will be merged with study data to assess the effect

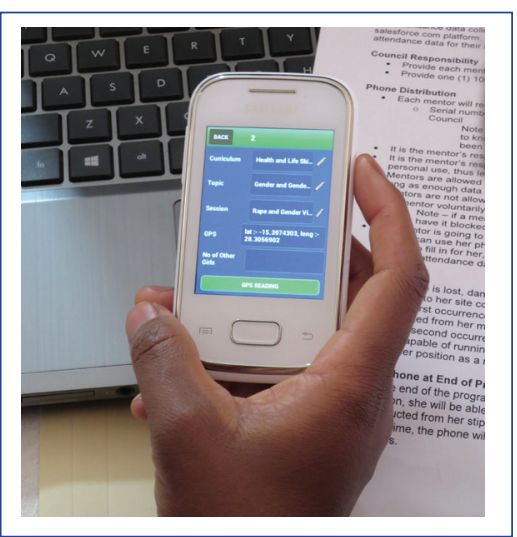
of the level of program participation on program outcomes.

\section{RECOMMENDATIONS/CHANGES FOR ROLLOUT}

- Development of an electronic registration and attendance system for AGEP based on two mobile apps and a web-based system for tracking attendance.

\section{Recruitment (Introductory Meetings/Registration Tables)}

A key challenge throughout the pilot was enrolling girls into the program and ensuring their participation on a regular basis. One the challenges of recruitment was the sequence of the introductory events. During the pilot, the registration process included three meetings: 1) an introductory meeting where girls came with their guardians, 2) a second introductory meeting just for the girls where they were divided into groups, and 3) their first safe spaces meeting. This was found to be a) too many meetings, and many girls did not attend all and were never assigned to a group, b) girls and/or guardians couldn't attend meetings at the specified time and c) in rural areas, only having one meeting location meant that some girls in the large CSAs had to travel quite far. One introductory meeting was held per CSA. In addition, all girls were together in the introductory meetings and the older girls disliked being grouped together with the younger girls. 


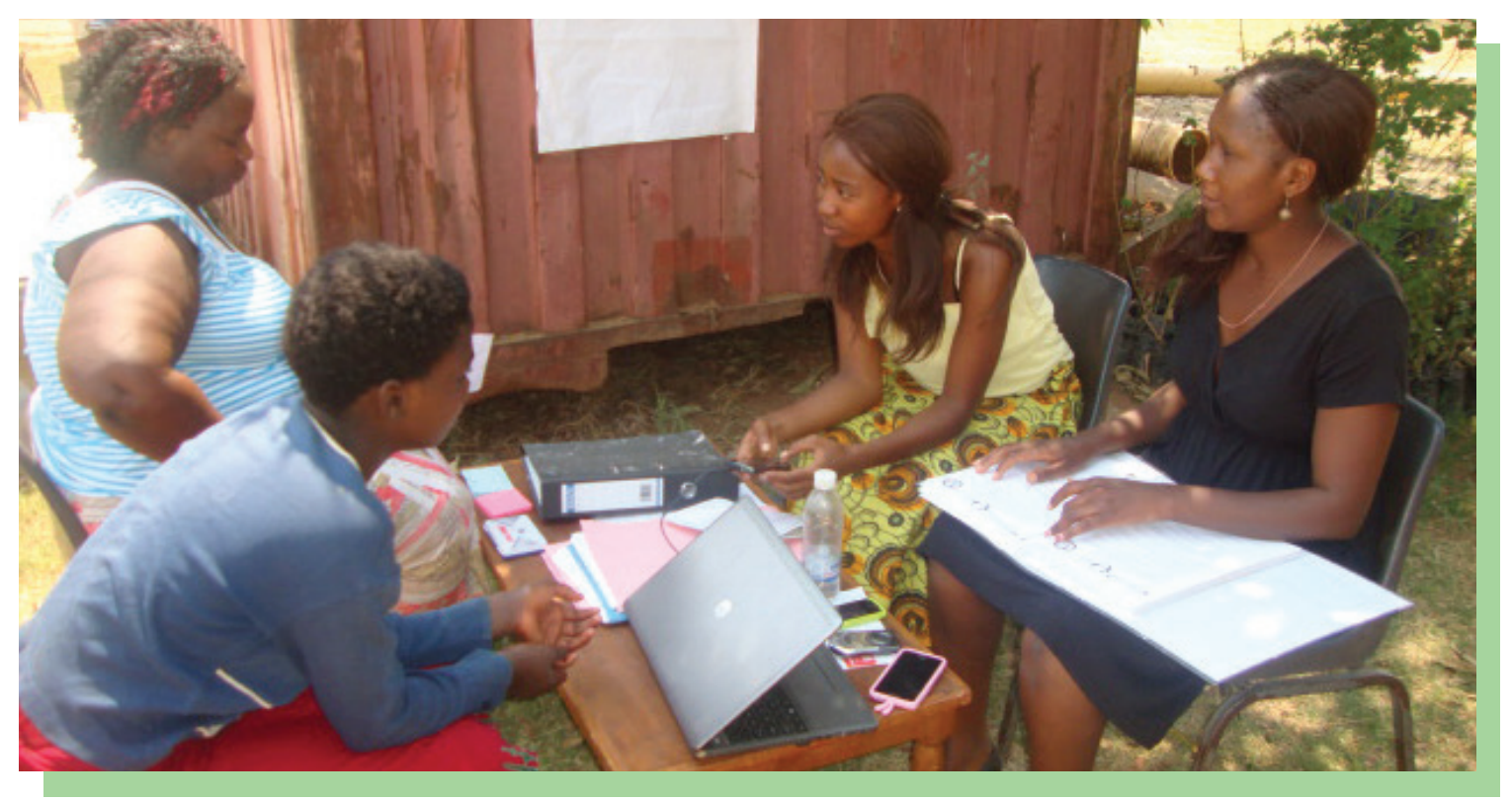

Another challenge was that girls would bring friends to join, and they were turned away because only invited girls were allowed to participate. This sometimes discouraged the invited girls from joining and participating. In other cases, not all of the girls in a household were invited, and girls or parents were discouraged from allowing those who were invited to join if they could not all join.

RECOMMENDATIONS/CHANGES FOR ROLLOUT:

- Have only one introductory meeting for girls and their guardian and assign girls to groups at that first meeting.

- Add registration tables for the week after the introductory meeting so that girls/guardians could come on a one-on-one basis to register if they missed the introductory meeting.

- In large CSAs in rural areas, hold more than one introductory meeting to minimize distance travelled.

- Separate girls ages 10-14 and 15-19 during introductory meetings.

- Allow girls to bring friends for the first eight weeks, and after eight weeks, register those initial girls. Groups will not know what curriculum they are until after the eight-week registration period is closed so as to avoid "jumping" to different groups.

- If a girl is selected from a household that has additional girls, invite all the other 10-19-year-old girls in that household as well.

\section{Retention}

In addition to enrolling girls in the program, there was a challenge of regular attendance at safe spaces meetings during the pilot period. Each week, on average, about 42 percent of registered girls attended, falling short of the 75 percent target. Mentor inconsistencies contributed to this problem (see above); however, it was also felt that girls needed incentives for participation. It was not financially feasible to provide snacks at each meeting, therefore an attendance passport was developed where a girl gets a stamp for each meeting attended. She will receive small prizes for every

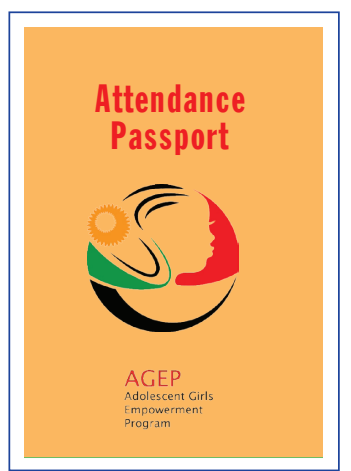


ten meetings that she attends. Another feedback from the pilot was that girls were losing interest in being trained week after week.

RECOMMENDATIONS/CHANGES FOR ROLLOUT

- Introduction of an attendance passport where girls get a stamp for each meeting attended and a small prize for every ten meetings attended.

- Once every other month, the group meeting will be a 'fun-day'-a time for girls to play sports, dance, perform drama, and just talk, without including a formal training session,

\section{HEALTH VOUCHER}

At the time of this report, the voucher has been active for only one month in the two pilot sites. Therefore, the full evaluation from the pilot period is not yet available and will be published at a later time. However, some initial insights are available given the extended process in setting up the voucher. Much time was spent in getting the necessary agreements in place, both with the $\mathrm{MoH} / \mathrm{MCDMCH}$ and the private providers. While timeconsuming, it is critical to be clear about: fee reimbursement, reimbursement channels, medical protocols, fraud prevention, provider training, reporting requirements, and more.

In addition, time was spent developing a two-part training for the providers, both public and private. The first focused on the delivery of adolescentfriendly health services (AFHS), including values clarification, needs of adolescence, and the medical protocols for each of the services offered on the voucher. The second focused on the specific mechanics of the voucher, which requires the provider to send in SMSs for authorization and confirmation of each service provided. Training had to be conducted over four afternoons, because providers could not be pulled out for full days. In addition, each clinic was

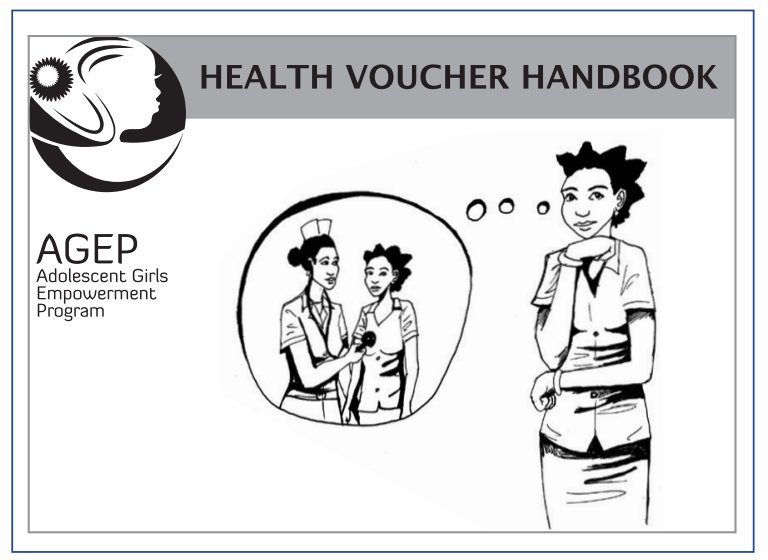
trained separately on-site so that providers did not have to be absent from their clinic and to save on costs. In this way, more providers in each clinic could be trained and thus not rely on a TOT model, which is not always the most effective. Furthermore, non-providers were also included-gatekeepers such as receptionists, clerks, and/or community health workers-who are often involved in registration of clients and/or the initial screening upon arrival at the health center.

Girls also need training on how to use the voucher, and given that many are low-literacy or illiterate, the use of pictures to illustrate the process is critical. A low-literacy voucher handbook was created. Finally, girls would benefit from a visit to the clinics, especially the private ones that they may not be familiar with from the community, to encourage voucher use.

RECOMMENDATIONS/CHANGES FOR ROLLOUT

- Give ample time to get all agreements in place

- Ensure applicability for low/no-literacy girls with IEC materials on the voucher

- Train health care providers at a time and location that is convenient for them 


\section{SAVINGS ACCOUNT}

The development of the savings account started with a search for the appropriate financial institution partner. NatSave was chosen as a result of 1) support from the Managing Director, 2) a match between their mission to reach the financially excluded and the target population of AGEP, 3) their experience developing products for special market segments and 4) their belief that a girl's account fits into their business model.

After selecting the financial institution partner, market research was conducted with adolescent girls in rural and urban areas, in school and out of school, and younger and older to determine both their cash flow and needs/preferences for a savings product. Key findings were that 1) adolescent girls in the targeted communities have sufficient existing (or potential) income sources and flexible enough expenditure patterns to be able to save money (on a regular, seasonal, or irregular basis); 2) adolescent girls in the targeted communities are already motivated to save money (or can become motivated via financial literacy \& safespaces mentoring programs); and 3 ) adolescent girls in the targeted communities would choose to use a NatSave adolescent girls savings account product (if designed appropriately across all product features) in order to save money (towards short and/or long term goals).

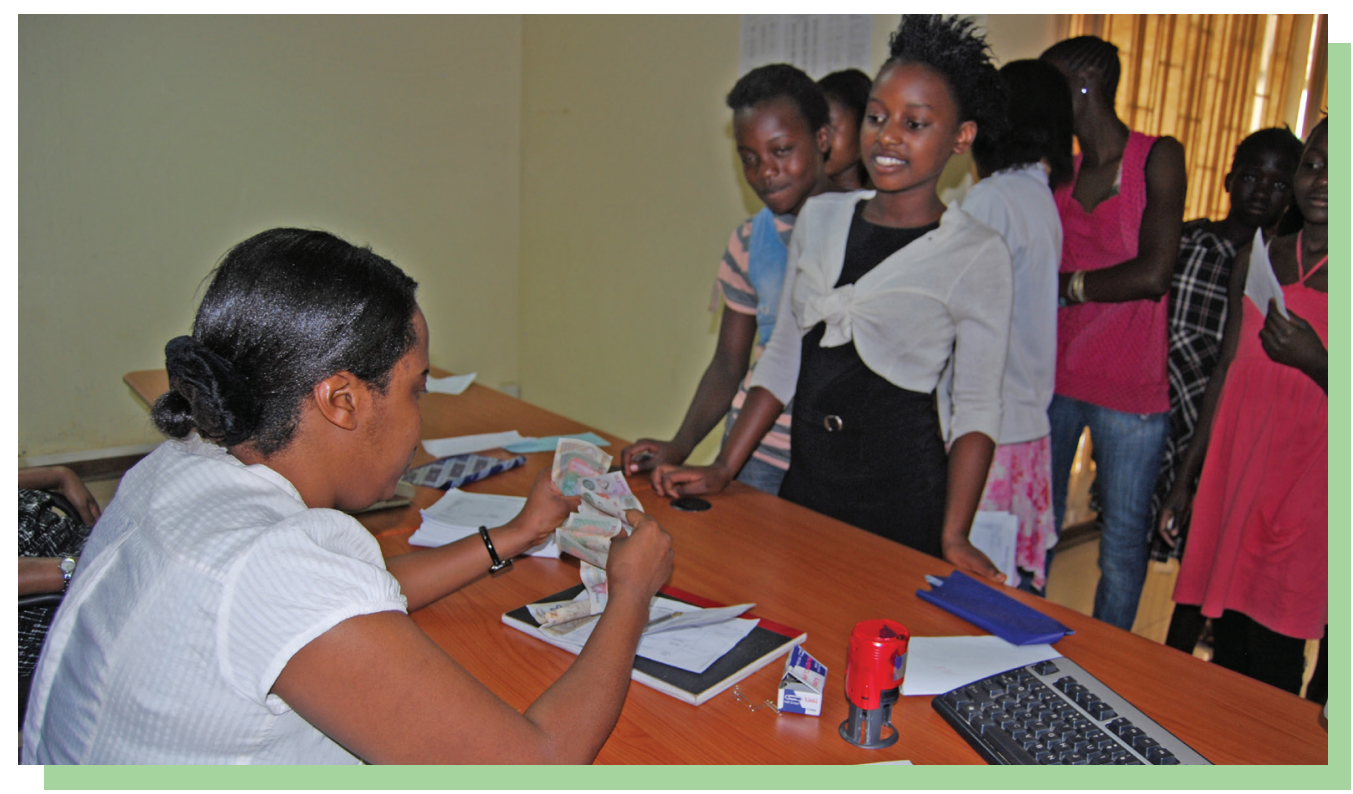

\section{KEY RECOMMENDATIONS FROM THE MARKET RESEARCH:}

- Work with a financial institution that has commitment from top management.

- Work at branch level to build buy-in for the product among branch manager and frontline staff.

- Reach an agreement with the financial institution and the country's regulatory body (typically a Central Bank) on girl-friendly KYC requirements.

- Do not make assumptions on what girls want in a savings product-ask them directly!

- Balance girls' preferences with bank demands to ensure a viable and sustainable product.

After a year of pilot-testing the saving account in both the rural and urban areas, key challenges arose that led to changes for the pilot period. First, many girls were not able to open accounts because of the complicated nature of account opening and their lack of the required documentation. Since account opening took place during an organized visit to the branch, girls who were unable to complete the process on site did not return to the bank to open the 
account on their own. Second, the distance to the branch was a challenge in both urban and rural settings, but more so in rural settings. Third, more support was needed from cosigners, and within the safe spaces groups to encourage for saving. Finally, branch staff did not consistently create a youth-friend environment for Girls Dream Account holders-creating a barrier for girls who wished to return to make additional transactions on their accounts.

RECOMMENDATIONS/CHANGES FOR PILOT:

- Account opening will occur at the group level, and then a visit to the bank will be organized to make the first deposit.

- NatSave will introduce agency banking ${ }^{3}$ so that girls in rural areas will have a point of transaction closer than the nearest town branch.

- Training of NatSave bank staff will take place at HQ and branch levels, with an emphasis on the importance of creating a youth-friendly environment.

- More work will be done on the program side to sensitize parents/guardians/husbands, and to link the financial education to savings activities at the group level.

\section{CONCLUSION}

The pilot period of AGEP has been critical to the success of the overall program. First, all key components of the intervention have been designed-the safe spaces, the mentor training curricula, the health and life skills curriculum, the financial education curriculum, the girls savings account, the health voucher, and key research design implementation steps. After development, implementation was tested and provided key lessons learned that have led to adaptations that will enhance the rollout intervention.

In the next two years, AGEP will roll out to 10 additional sites in Zambia, five urban and five rural, reaching a total of 10,000 vulnerable girls ages $10-19$. Over 6,000 vouchers will be distributed and 3,000 savings accounts opened. Over 350 safe spaces groups will be formed and 35,000 safe spaces meetings held. The research study will provide precise results on how all of these activities affected the participants, and given to the three study arms, we will document the added benefits of both the health voucher and savings accounts. While the results will focus on the main impact indicators of school attainment, HIV prevalence, HSV-2 prevalence, age at marriage, age of sexual initiation, age of first birth and experience of sexual violence, there will be an abundance of learning about effects on self-esteem, agency, gender norms, savings activity, income generation, health service seeking, and nutritional status-both as outcomes on their own and as pathways to the longer-term impacts of the program. Furthermore, we will determine the cost of delivering each program component, and what it costs to achieve each additional benefit. It is our expectation that this learning and evidence will provide guidance for scale up of the program in Zambia and elsewhere.

\section{REFERENCES}

Brady, Martha et. al. 2009. “Understanding Adolescent Girls' Protection Strategies Against HIV: An Exploratory Study in Zambia.” New York: Population Council.

Bruce, Judith. 2007. "Girls left behind: Redirecting HIV interventions toward the most vulnerable." Transitions to Adulthood Brief no. 23. New York: Population Council.

3 Agency banking is the use of third-parties (e.g., a shop owner), furnished with a point-of-sale device that is networked to the NatSave systems, to create a location at which account holders can make transactions without having to travel to the branch. 


$$
\text { [5] }
$$

(P) Population Council 